OPEN ACCESS

Editado por:

Dr. Victor Hugo Gomes Sales Instituto Federal do Amapá, Macapá-AP, Brasil

Seção:

Esse artigo foi submetido em Ciências Agrárias, uma seção do Journal of Bioenergy and Food Science

ID JBFS2622019

DOI 10.18067/jbfs.v6i4.262

Processos de revisão: Prot. 2622019R01 (Brasil) Prot. 2622019R02 (Brasil)

*Autor correspondente:

Deny Cesar Moreira denymoreira@yahoo.com

Conflito de interesse:

Os autores declararam que não há conflito de interesse.

Financiamento

Os autores declararam que não receberam financiamento para o desenvolvimento da pesquisa.

Recebido em: 21 de fevereiro de 2019

Aceito em: 10 de agosto de 2019

Publicado em: 01 de outubro de 2019

Citação (APA):

Moreira, D.C., Collicchio, E., \& Gamba, F.B.

(2019). Panorama do cultivo e produtividades da soja na APA Ilha do Bananal/Cantão Tocantins: Safras 2008/2009 a 2015/2016 Journal of Bioenergy and Food Science, 6(4) 119-131. doi: 10.18067/jbfs.v6i4.262

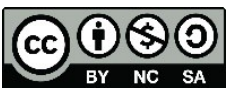

JBFS all rights Copyright: (C) 2019

\section{Panorama do cultivo e produtividade da soja na APA Ilha do Bananal/Cantão, Tocantins: safras 2008/2009 a 2015/2016}

Overview of soybean cultivation and productivity in Bananal/Cantão Island Protected Area, Tocantins: harvests $2008 / 2009$ to $2015 / 2016$

1,* Deny Cesar MOREIRA, ${ }^{1,2}$ Erich COLLICCHIO, e ${ }^{1, \mathbb{D}}$ Fábio Brega GAMBA

${ }^{1}$ Universidade Federal do Tocantins (UFT), Campus Palmas-TO. Quadra 109 Norte, Avenida NS15, ALCNO-14 - Plano Diretor Norte, 77001-090. Palmas - TO. Brasil.

2 Laboratório de Agroenergia, Uso da Terra e Mudanças Ambientais (LAMAM/UFT). Palmas-TO. Brasil

RESUMO

A Área de Proteção Ambiental (APA) Ilha do Bananal/Cantão é maior Unidade de Conservação do Tocantins e integra a segunda maior região produtora de soja do Estado, estabelecendo uma relação de interesses econômicos, sociais e ambientais muitas vezes conflitantes. Este artigo apresenta a evolução e os principais fatores que envolvem a cultura da soja na APA. Por meio de pesquisas bibliográficas, visitas a campo e entrevistas com os sojicultores da Unidade, ficou demonstrado o crescimento de mais de $1.700 \%$ das áreas de plantio de soja em um período de 8 anos, no qual houve significativo desmatamento na região. Também foi identificado que o cultivo ocorre em grandes latifúndios, impulsionado pelo clima e pelos baixos preços das terras, sendo a falta de mão de obra qualificada a principal dificuldade encontrada pelos sojicultores. Identificou-se também o não cumprimento da legislação ambiental por parte dos produtores locais.

Palavras-chave: Área de Proteção Ambiental. Unidade de Conservação. Sojicultura

ABSTRACT

The Bananal/Cantão Island Protected Area (APA) is the largest Protected Área in Tocantins State and is the second largest soybean producing region in the Tocantins, establishing a relationship of economic, social and environmental interests that are often conflicting. This article presents the evolution and the main factors that involve the soybean crop in APA. By means of bibliographical researches, field visits and interviews with the soybean farmers of the APA, it was demonstrated the growth of more than $1,700 \%$ of the areas planted with soybeans over a period of 8 years, in which there was significant deforestation in the region. It has also been identified that cultivation takes place in large property, encouraged by the climate and low land prices, and the lack of skilled labor is the main difficulty encountered by soy farmers. It was also identified the noncompliance of environmental legislation by local producers.

Keywords: Environmental Protection Area. Conservation Unit. Soybean crop 


\section{INTRODUÇÃO}

O Estado do Tocantins é o nono maior Estado brasileiro com uma área de $277.720,569 \mathrm{~km}^{2}$, uma população de 1.383 .453 habitantes e integra a região denominada Amazônia Legal (IBGE, 2010; IBGE, 2014).

O Estado possui $91 \%$ de toda sua área ocupada pelo bioma Cerrado e o restante pela Floresta Amazônica, sendo que dentro de cada bioma ocorrem variações quanto à fisionomia da vegetação característica (SILVA, 2007). A vocação do Estado para a agricultura é promovida, entre outros, pela Secretaria Estadual de Agricultura e Pecuária, a qual enaltece o Tocantins como "o novo polo agrícola do Brasil", afirmando que metade do seu território possui potencial para a agricultura com terras férteis e de valor competitivo, topografia plana favorecendo o processo de mecanização agrícola, clima quente e homogêneo, fotoperiodicidade favorável à alta produtividade e muita disponibilidade de água para irrigação (SEAGRO, 2016).

Economicamente o agronegócio demonstra sua força como um dos pilares da economia do Estado, visto que, no Tocantins, o setor responde por $16 \%$ do Produto Interno Bruto ${ }^{1}$, enquanto que em outros Estados, a média é de 5\% (SEPLAN, 2016). Porém, antes do Tocantins ter alcançado esse status de "novo polo agrícola do Brasil", Nascimento (2013, p.112) afirmou que "a agropecuária tocantinense, apesar de ter sido uma das primeiras atividades econômicas, ficou, por quase dois séculos, limitada a uma produção para "autoconsumo". Esse cenário começou a se alterar na década de 1960, com a construção da rodovia Belém-Brasília por meio da qual foi intensificada a chegada de migrantes que expandiram as frentes extrativistas e ocuparam a área da bacia hidrográfica Tocantins-Araguaia (se aproximando da margem direita do rio Araguaia) possibilitando, a quebra do isolamento geográfico, a implantação de grandes fazendas, a chegada de instituições públicas, do financiamento bancário e promovendo a privatização da terra e a mercantilização da economia regional (ALVES, 2015; NASCIMENTO, 2013).

Com o passar das últimas décadas, o perfil do uso e ocupação das terras no Estado foi sendo alterado de forma mais intensa à medida que as pequenas propriedades foram sendo compradas pelas grandes empresas agrícolas, ocorrendo a expansão das culturas de exportação, como a cana-de-açúcar e a soja (GRAZIANO NETO, 1982 apud FORNARO, 2012) sendo que, de acordo com Alves (2015), a partir da década de 70 que empresas agrícolas se estabeleceram ao longo do vale do Rio Araguaia, na parte oeste do Estado do Tocantins, atraídas por incentivos fiscais dados pelo governo.

Segundo Nascimento (2013), as pequenas fazendas, até então caracterizadas por uma economia de subsistência e voltadas principalmente às necessidades imediatas de consumo alimentar, foram substituídas pelo agronegócio, contribuindo para a mudança do perfil agrícola do Estado, agora caracterizado por uma agricultura moderna, voltada para a produção de excedente. Nesse contexto o Tocantins também apresenta vantagens com relação à logística, uma vez que o Estado está estrategicamente localizado no centro do país e vem implantando a ferrovia NorteSul em toda sua extensão, um componente logístico importante que faz com que a produção agrícola dos municípios seja transportada com maior velocidade, eficiência

\footnotetext{
${ }^{1}$ Dados referentes a 2011.
} 
e a custos menores (NASCIMENTO, 2013), interligando o interior do país aos centros consumidores e áreas portuárias das regiões nordeste e sudeste.

O cultivo da soja no Estado ocorreu principalmente a partir do final dos anos de 1990, a partir da vinda de agricultores das regiões Sul, Sudeste e Centro-Oeste do Brasil em busca de terras e custos de produção mais baratos (DA SILVA, 2007). Atualmente, segundo dados da Secretaria de Planejamento e Modernização da Gestão Pública do Estado do Tocantins, a soja predomina a produção de grãos no Estado, correspondendo, em 2014, a 62,24\% do total produzido (SEPLAN, 2016). Segundo levantamento da Companhia Nacional de Abastecimento, referente à safra 2015/2016, a área plantada de soja no Tocantins foi de 870,85 mil hectares, com uma produção de 1.686,43 mil toneladas (CONAB, 2016). A relevância da cultura da soja no mundo tem incentivado o crescimento do plantio em todo o país. Atualmente o Estado do Tocantins responde pelo oitavo lugar no ranking nacional, com 2,57\% da produção brasileira (SANTOS, 2015).

Segundo Santos et al. (2015), dados da Associação Brasileira das Indústrias de Óleos Vegetais, apontam que, dos 40,1 milhões de toneladas de soja previstas para 2015 , 30,4 milhões de toneladas seriam destinadas a produção de farelo e 7,95 milhões de toneladas para a fabricação de óleo, das quais 3 milhões de toneladas irão originar biodiesel.

Em 2015, foram produzidos no País, 3.937.269 $\mathrm{m}^{3}$ de biodiesel, o que significou um aumento de $15,1 \%$ desse produto disponibilizado no mercado interno. 0 percentual de biodiesel adicionado compulsoriamente ao diesel mineral cresceu para 7\% em novembro de 2014 e tem se mantido assim desde então. Esse aumento da mistura obrigatória de biodiesel no diesel utilizado nos veículos brasileiros foi determinante para o aumento na produção de óleo de soja (SANTOS et al., 2015, p.46).

Toda essa expansão agrícola da soja nas últimas décadas transformou o Cerrado em uma potência agrícola, mas cobrou um preço alto dos recursos naturais. O bioma que é considerado um dos hotspots ${ }^{2}$ mais ameaçados do planeta e tem sido bruscamente modificado desde a década de 70, afetando principalmente os recursos naturais através da perda da vegetação nativa (ROCHA, 2012).

Dentro do contexto ambiental buscou-se aqui, apresentar o estado da arte da cultura da soja na maior Unidade de Conservação do Estado do Tocantins, a Área de Proteção Ambiental Ilha do Bananal/Cantão e identificar, junto aos sojicultores da Unidade, quais os principais fatores que envolvem a produção local desse grão.

\section{MATERIAL E MÉTODOS}

\section{a) Área de estudo}

Localizada na região oeste do Estado (Figura 1), a Área de Proteção Ambiental Ilha do Bananal/Cantão possui uma área de $16.780,00 \mathrm{~km}^{2}$, o equivalente a $6,04 \%$ de todo o território do Tocantins e $40,07 \%$ de todas as áreas de Unidade de Conservação

2 O termo "Hotspot" designa áreas extremamente ricas em biodiversidade definidas com base em dois critérios principais: número de espécies endêmicas existentes e alto grau de ameaça a essas espécies. Dos 34 hotspots existentes no mundo, apenas dois estão no Brasil, sendo que o Cerrado é um deles (MYERS et al., 1988). 
do Estado, incluindo as de domínio federal, estadual e municipal. (TOCANTINS, 1997; SEPLAN, 2012).

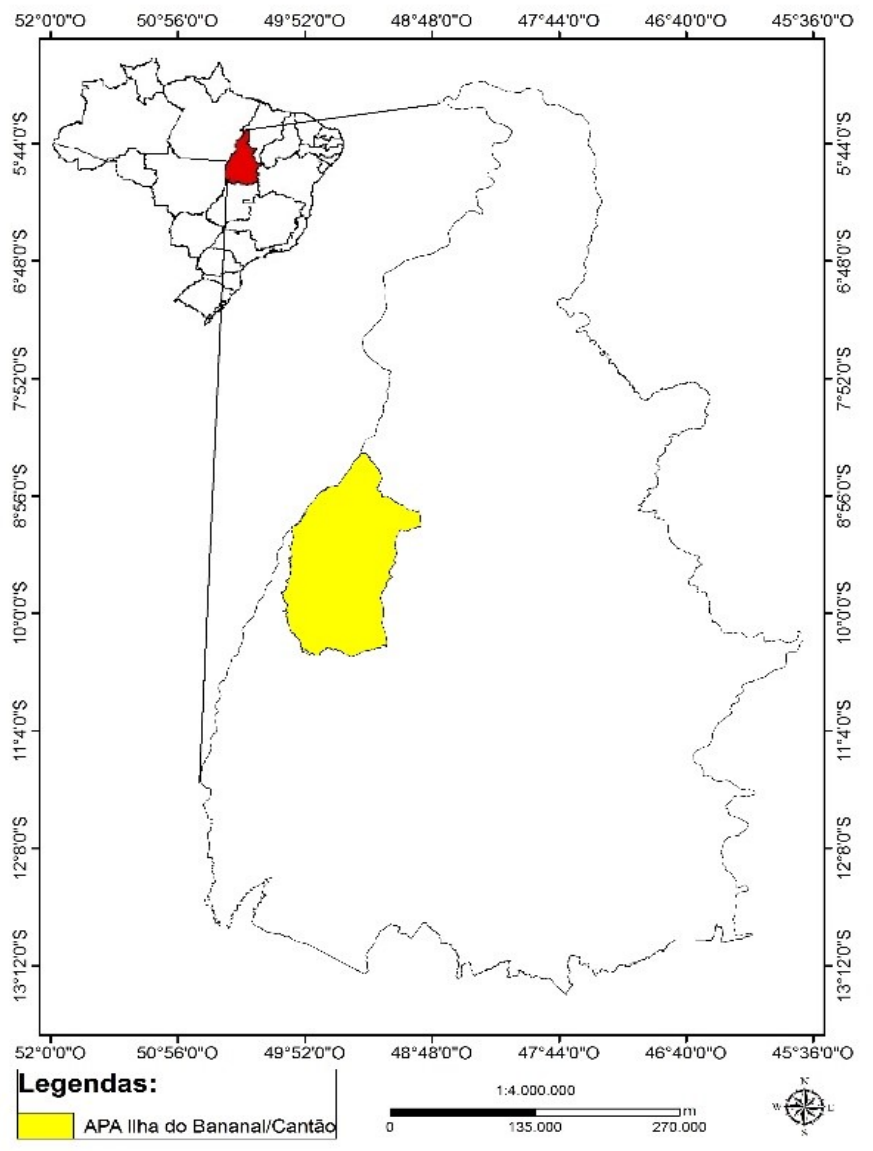

Figura 1. Localização da APA Ilha do Bananal Cantão

Fonte: Elaborado a partir de NATURATINS (2016).

Figure 1. Location of Bananal/Cantão Island APA, Tocantins State

Source: Elaborated from NATURATINS (2016)

Segundo o Sistema Nacional de Unidades de Conservação, as Áreas de Proteção Ambiental são áreas geralmente extensas constituídas por terras públicas ou privadas, e com certo grau de ocupação humana, tendo como objetivos básicos a proteção da biodiversidade, assegurar a sustentabilidade dos recursos naturais e disciplinar o processo de ocupação em seu interior (BRASIL, 2010). Segundo Motta (1997) apud SEINF (2000), as Áreas de Proteção Ambiental devem manter sua destinação e vocação natural, ou seja, o que existia antes de sua criação permanece existindo, porém sob atuação de uma legislação de proteção ambiental específica e mais rígida.

A Área de Proteção Ambiental Ilha do Bananal/Cantão abrange nove municípios, três dos quais encontram-se totalmente inseridos na Unidade (NASCIMENTO, 2013; SEPLAN, 2012). Em sua maioria a Área de Proteção Ambiental apresenta vegetação de Cerrado, além de uma pequena porção representada pela região da floresta estacional semidecidual, áreas essas de transição para a Floresta Amazônica (SEINF, 2000; SEMARH, 2016).

Os baixos índices de declividade (igual ou inferior a 5\%) predominam no território da Área de Proteção Ambiental não impedindo ou dificultando o trabalho de qualquer tipo de máquina agrícola mais usual. Em sua maior parte, o escoamento superficial é lento ou médio e a erosão hídrica não oferece maiores problemas 
(SEPLAN, 2008). O clima predominante nesta região é quente e úmido com estações bem definidas e período seco entre os meses de junho a agosto. $O$ período mais chuvoso oscila entre janeiro e fevereiro, sendo que o período com maior umidade ocorre normalmente de janeiro a março. Caracteriza-se pela oscilação de temperaturas médias e índices pluviométricos elevados (SANTOS, 2003).

A Companhia Nacional de Abastecimento divide o Estado do Tocantins em três regiões produtivas, sendo que a região onde estão incluídos os municípios que compõem a Área de Proteção Ambiental Ilha do Bananal/Cantão aparece como a segunda maior em área plantada de grãos do Estado, com 39,66\%, além de ser também a segunda maior em área plantada de soja, respondendo por 37,61\% da área plantada do Estado (CONAB, 2016).

\section{b) Metodologia}

Para apresentação da evolução da cultura da soja na Área de Proteção Ambiental llha do Bananal/Cantão, foi realizada a busca por dados secundários através de pesquisas bibliográficas e consultas a instituições públicas e privadas ligadas ao setor agropecuário e ambiental do Estado.

Para identificação dos principais fatores que envolvem a cultura da soja na Área de Proteção Ambiental, a metodologia aplicada foi a realização de entrevistas semiestruturadas com os sojicultores da Unidade, tarefa essa que demandou inicialmente identificar todas as propriedades produtoras de soja localizadas nos municípios que compõem a Área de Proteção Ambiental Ilha do Bananal/Cantão. As identificações dessas propriedades, incluindo a coordenada geográfica das sedes de cada uma delas, foram fornecidas previamente pela Agência de Defesa Agropecuária do Tocantins. De posse dessas informações foi elaborado um roteiro prévio de visitas apenas às propriedades localizadas, total ou parcialmente, dentro da Área de Proteção Ambiental.

As saídas a campo, objetivando visitar cada uma dessas propriedades selecionadas previamente e aplicar o questionário junto aos responsáveis, ocorreram em duas etapas nos meses de outubro e novembro de 2016. Ao todo foram identificadas 44 propriedades, das quais 42 (localizadas nos municípios de Abreulândia, Araguacema, Caseara, Divinópolis, Marianópolis e Pium) foram visitadas, representando um universo amostral de $95,45 \%$ e as respostas obtidas foram registradas individualmente em um questionário e tiveram o áudio gravado no formato mp3 para eventuais consultas posteriores.

\section{RESULTADOS E DISCUSSÃO}

O primeiro registro da produção de soja nos municípios que compõem a Área de Proteção Ambiental Ilha do Bananal/Cantão, segundo os dados do Instituto Brasileiro de Geografia e Estatística, ocorreu no ano de 2000, com uma área plantada de 30 hectares. Entretanto, foi apenas a partir de 2008 que esses dados passaram a ser coletados, na região, de forma sistemática, com periodicidade anual.

A Tabela 1, a seguir, apresenta a evolução da área plantada de soja nos municípios que compõem a Área de Proteção Ambiental Ilha do Bananal/Cantão, a partir da safra 2008/2009, bem como as mesmas séries históricas referentes ao Estado e ao país. 
Tabela 1. Evolução da área plantada de soja por município que compõem a Área de Proteção Ambiental Ilha do Bananal/Cantão (mil ha), entre 2008/2009 a 2015/2016.

Table 1. Evolution of planted area with soybean by municipality that makes up the Bananal/Cantão Island Environmental Protection Area (thousand ha), between 2008/2009 to 2015/2016.

\begin{tabular}{lcccccccc}
\hline Municípios APA & $2008 / 09$ & $2009 / 10$ & $2010 / 11$ & $2011 / 12$ & $2012 / 13$ & $2013 / 14$ & $2014 / 15$ & $2015 / 16$ \\
\hline Abreulândia & - & - & - & - & - & - & 0,28 & 5,35 \\
Araguacema & 0,6 & 0,8 & 0,5 & 2,5 & 2,4 & 2,5 & 5,5 & 7,45 \\
Caseara & 0,5 & 0,5 & 0,6 & 0,55 & 2,1 & 4,0 & 11,2 & 11,4 \\
Chapada de Areia & - & - & - & - & - & - & - & - \\
Divinópolis & - & - & - & - & - & - & 0,63 & 3,0 \\
Dois Irmãos & 1,32 & 0,8 & 1,0 & 0,9 & 0,6 & 0,6 & 0,65 & 0,67 \\
Marianópolis & - & & & & & 5,0 & 6,2 & 15,0 \\
Monte Santo & - & - & - & - & - & - & - & - \\
Pium & 0,5 & 0,64 & 1,5 & 1,4 & 3,7 & 1,34 & 4,34 & 9,9 \\
\hline Total & 2,9 & 2,7 & 3,6 & 5,3 & 8,8 & 13,4 & 28,8 & 52,7 \\
\hline Tocantins & 311,4 & 364,3 & 404,7 & 451,2 & 549,6 & 748,4 & 849,6 & 870,8 \\
\hline Brasil & $21.743,1$ & $23.467,9$ & 24.181 & $25.042,2$ & $27.736,1$ & $30.173,1$ & $32.092,9$ & $33.251,9$ \\
\hline
\end{tabular}

Fonte: Elaborado a partir de IBGE (2016); BRASIL (2017).

Source: Elaborated from IBGE (2016); BRASIL (2017)

Nota-se, na Tabela 1, que o crescimento da área de plantio de soja como um todo nos municípios que compõem a Área de Proteção Ambiental foi superior a $1.700 \%$ no período de 2008 a 2016 e que os três municípios que apresentaram maior área cultivada, Marianópolis, Caseara e Pium, representam juntos $68,78 \%$ da área total da cultura produzida na região. Outro dado que chama atenção é o crescimento da área plantada no município de Araguacema, o qual saltou de 280 hectares na safra $2014 / 2015$ para 5.350 hectares na safra seguinte, uma expansão superior a $1.800 \%$ ocorrida de um ano para outro. Esse aumento contínuo das áreas de soja é um fato em todo o Estado, porém, nos últimos anos, esse crescimento ocorreu proporcionalmente de forma muito mais expressiva nos municípios que compõem a Área de Proteção Ambiental (Figura 2).

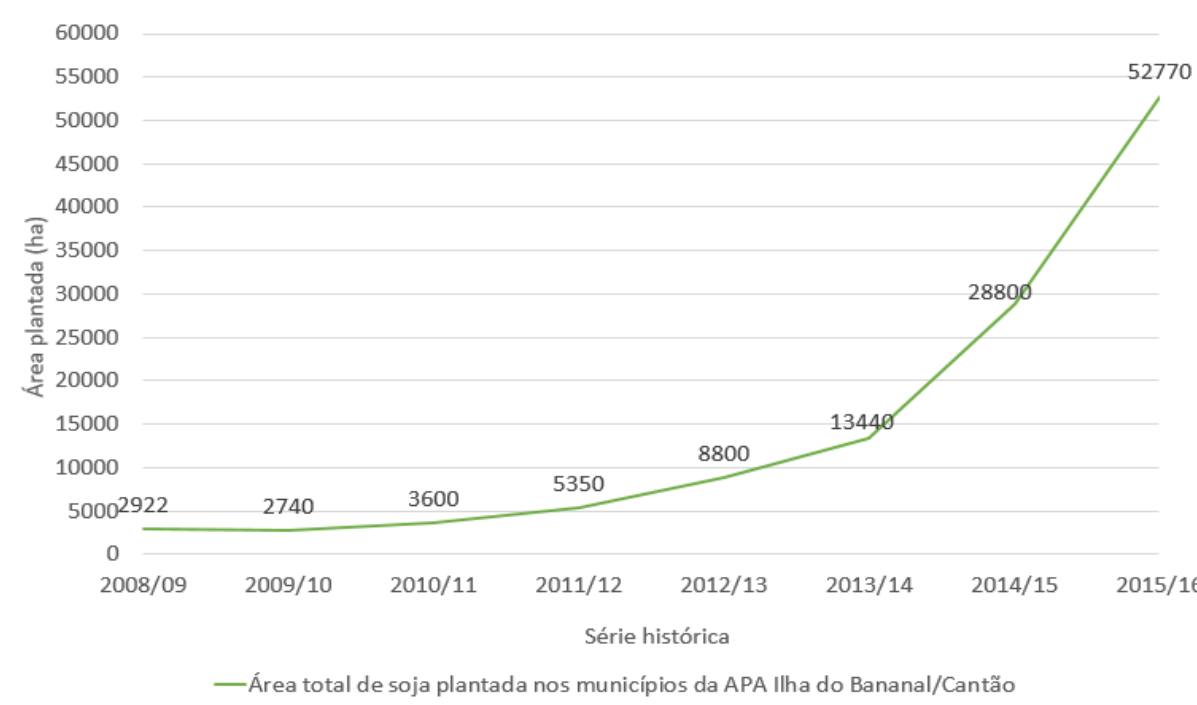

Figura 2. Série histórica da área plantada de soja nos municípios da APA Ilha do Bananal/Cantão (safra $x$ área/ha)

Fonte: Elaborado a partir de IBGE (2016).

Figure 2. Historical series of planted area with soybean in the municipalities of the Bananal/Cantão Island APA (crop area/ha)

Source: Elaborated from IBGE (2016) 
A Tabela 2 a seguir apresenta, a partir dos dados de área plantada de soja, a variação percentual do aumento dessas áreas em relação a safra anterior, tanto no Estado quanto nos municípios que compoem a Área de Proteção Ambiental, além da diferença percentual entre esses dados, referente ao período das safras 2009/2010 a 2015/2016.

Tabela 2. Variação percentual (\%) entre as áreas plantadas de soja no Estado do Tocantins e nos municípios que compõem a Área de Proteção Ambiental referente às safras de 2009/2010 a 2015/2016.

Table 2. Percentage variation (\%) between planted áreas with soybean in the state of Tocantins and the municipalities that make up the Bananal/Cantão Island Environmental Protection Area for the 2009/2010 to 2015/2016 harvests

\begin{tabular}{lccccccc}
\hline \multicolumn{1}{c}{ Regiões } & $2009 / 10$ & $2010 / 11$ & $2011 / 12$ & $2012 / 13$ & $2013 / 14$ & $2014 / 15$ & $2015 / 16$ \\
\hline Estado do Tocantins & 16,1 & 11,1 & 11,2 & 21,8 & 36,2 & 13,5 & 2,5 \\
Municípios da APA & $-6,2$ & 31,4 & 48,6 & 64,5 & 52,7 & 114,3 & 83,2 \\
\hline Diferença \% & & 182,9 & 333,9 & 195,9 & 45,6 & 746,7 & $3.228,0$ \\
\hline
\end{tabular}

Fonte: Elaborado a partir de IBGE (2016).

Source: Elaborated from IBGE (2016)

Nota-se que a partir da safra 2010/2011 (Tabela 2) a área de soja nos municípios que compõem a Área de Proteção Ambiental passou a superar percentualmente a área plantada no Estado. Enquanto a área plantada de soja no Estado cresceu 11,1\% da safra 2009/2010 para a safra 2010/2011, o crescimento nos municípios que compõem a Área de Proteção Ambiental no mesmo período foi de $31,4 \%$, o que representou uma diferença percentual em relação ao crescimento do Estado para a Área de Proteção Ambiental da ordem de 182,9\%. Os dados que mais chamam atenção, no entanto, referem-se às safras 2014/2015 e 2015/2016 cujas diferenças percentuais de crescimento da área plantada entre o Estado e os municípios que compõem a Área de Proteção Ambiental foram de $746,7 \%$ e 3.228,0\% respectivamente.

Os dados obtidos a partir da aplicação dos questionários demonstraram que o tamanho médio das propriedades que produzem soja na Área de Proteção Ambiental Ilha do Bananal/Cantão é de 4.082 hectares.

Com relação ao número de empregos diretos gerados por propriedade, constatou-se que 69\% delas geram de 1 a 10 empregos sendo que a média é de 15,1 empregos diretos por propriedade, o que representa uma taxa equivalente a 1 (um) trabalhador para cada 270 hectares. Segundo Carvalho (1999), o Estado do Maranhão apresenta uma média de 1 (um) trabalhador para cada 167 trabalhadores hectares, podendo chegar a 1 (um) trabalhador para cada 200 hectares nas maiores fazendas produtoras de soja. Esse número, de certa forma, respalda os dados obtidos na Área de Proteção Ambiental, considerando, certamente, a evolução da mecanização agrícola ocorrida nas últimas décadas, a qual vem automatizando cada vez mais a produção.

As principais atividades econômicas desenvolvidas nas propriedades produtoras de soja da Área de Proteção Ambiental Ilha do Bananal/Cantão são, respectivamente, a soja (83\%), a pecuária (14\%) e o milho (3\%).

Dados do Instituto Brasileiro de Geografia e Estatística (Figura 2) demonstraram que foi a partir da safra 2011/2012 que o crescimento das áreas plantadas de soja 
passou a ser mais acentuado na Unidade. Esses dados puderam ser confirmados em campo a partir da identificação de que $76 \%$ das propriedades visitadas iniciaram o plantio de soja há menos de 5 anos, 17\% delas entre 5 a 10 anos e $7 \%$ entre 11 e 20 anos.

A origem dos recursos financeiros utilizados no plantio de soja nas propriedades da Área de Proteção Ambiental é apresentada na Figura 3.

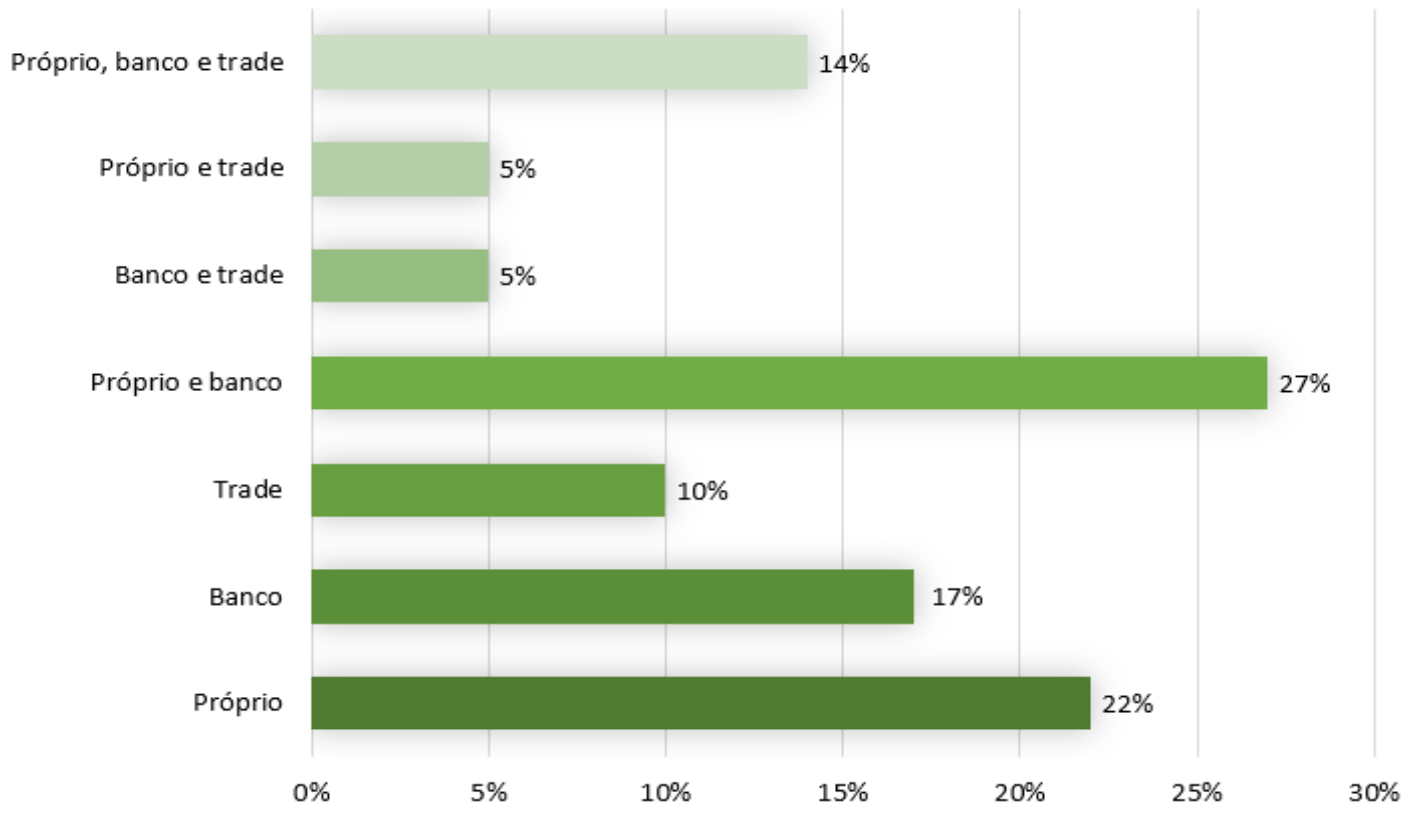

Figura 3. Origem dos recursos financeiros utilizados para o plantio de soja nas propriedades localizadas na APA Ilha do Bananal/Cantão

Figure 3. Source of financial resources used for soybean planting in properties located in the Bananal/Cantão Island APA

Fonte: Elaboração própria (2017)

Source: Own elaboration (2017)

Constatou-se que, em média, cada sojicultor plantou 1.192 hectares de soja na safra 2015/2016, o que equivale aproximadamente a $20 \%$ da área total da propriedade considerando o tamanho médio das propriedades e que $48 \%$ desses produtores desconhecem quais os produtos finais produzidos a partir da soja cultivada nas propriedades. Ainda assim identificou-se que os produtos mais produzidos a partir da soja cultivada nessas propriedades foram: ração animal, óleo vegetal e biodiesel.

Toda soja produzida nas propriedades visitadas é transgênica e todos os produtores entrevistados fazem uso de diversos tipos de inseticidas, herbicidas e fungicidas. Considerando que o Plano de Manejo da Área de Proteção Ambiental Ilha do Bananal/Cantão proíbe a utilização de agrotóxicos das classes I e II e analisando os dados obtidos sobre os agrotóxicos utilizados na unidade, constatou-se que $83,3 \%$ dos inseticidas, $71,4 \%$ dos herbicidas e $100 \%$ dos fungicidas atualmente utilizados pelos sojicultores entrevistados, não poderiam estar sendo utilizados por estarem em desacordo com o que é determinado no Plano de Manejo da Área de Proteção Ambiental. 
Quando observados esses dados dos agrotóxicos utilizados, em relação à origem dos recursos financeiros obtidos para cultivo da soja nas propriedades da Área de Proteção Ambiental, concluiu-se que $62 \%$ dos sojicultores fazem uso de algum sistema bancário para obtenção de recursos financeiros, provavelmente de crédito rural de instituição financeira pública, o qual tem financiado o uso de agrotóxicos altamente perigosos ao meio ambiente e extremamente tóxicos aos seres humanos. Quanto à dispersão desses agrotóxicos nas lavouras, identificou-se que $17 \%$ dos produtores o fazem por meio aéreo através do uso de aeronaves, enquanto os $83 \%$ restantes o fazem por meio de pulverizadores terrestres.

Objetivando evitar possíveis alagamentos das áreas de cultivo, alguns sojicultores fazem uso de uma técnica ambientalmente condenável. Trata-se da construção de valas de drenagem, popularmente chamada de "valões" no meio e/ou entorno das plantações, visando com isso escoar a água excedente dessas áreas cultivadas para áreas não cultiváveis, como florestas e corpos hídricos, podendo levar a sua contaminação pela lixiviação de agrotóxicos e o assoreamento dos corpos hídricos. Essa prática foi identificada em $38 \%$ das propriedades visitadas e pode ser observada na Figura 4.

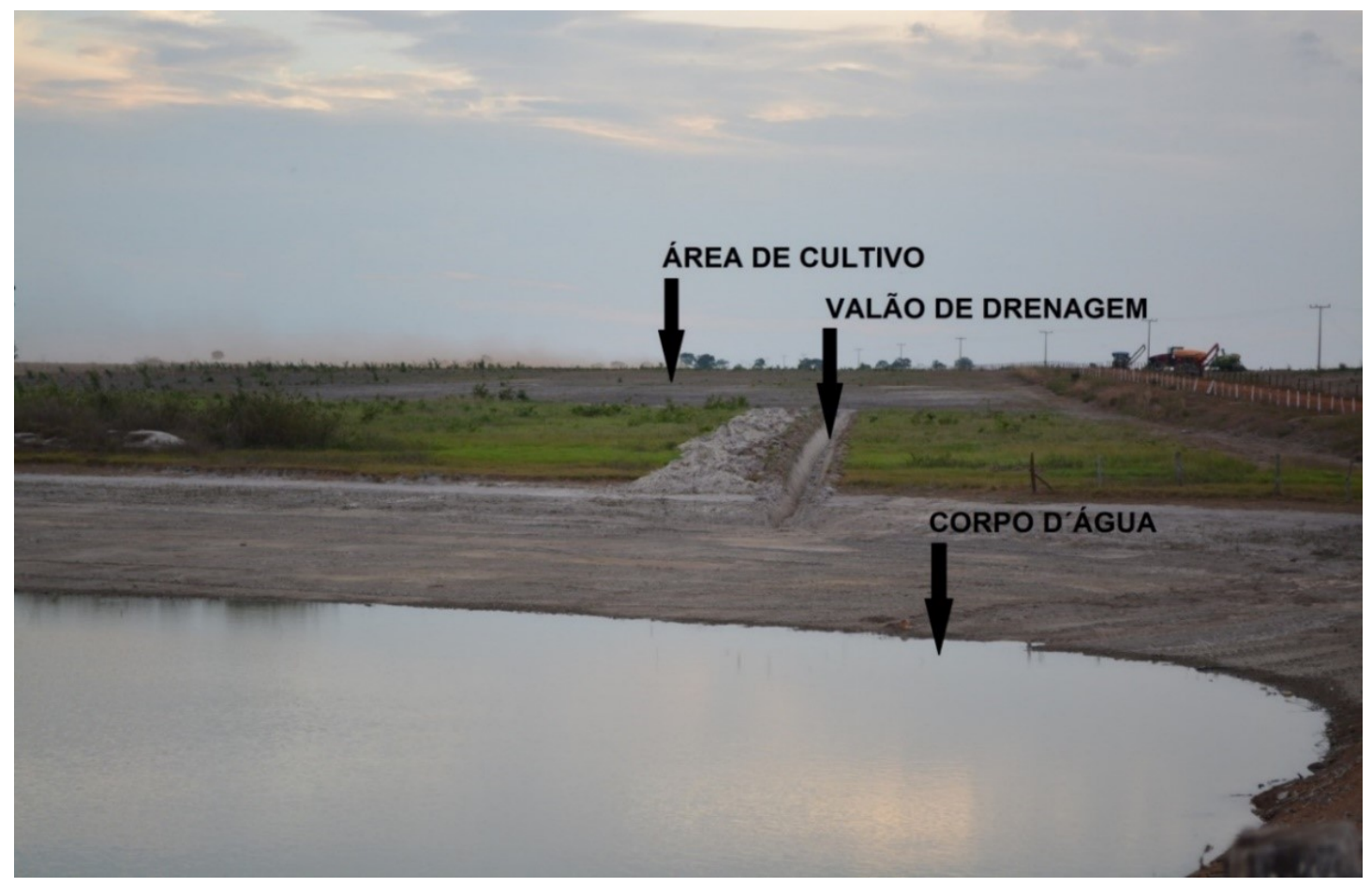

Figura 4. "Valão" de drenagem objetivando o escoamento de água da área de cultivo de soja para o corpo d'água - APA Ilha do Bananal/Cantão

Figure 4. Drainage "Valão" aiming at the flow of water from the soybean cultivation area to the body of water - Bananal/Cantão Island APA

Fotografia: Próprio autor (2017)

Photograph: Own elaboration (2017)

Segundo os sojicultores entrevistados, os principais motivos que os levaram a escolher a região oeste do Estado para local de desenvolvimento de suas atividades 
foram respectivamente: o clima, valor acessível da terra, qualidade do solo, topografia plana, a localização geográfica, disponibilidade de novas áreas e a possibilidade de cultivo de duas safras (soja e milho safrinha). Quando perguntado a esses mesmos sojicultores quais as principais dificuldades encontradas para o desenvolvimento das suas atividades, as respostas foram respectivamente: falta de mão de obra qualificada, excesso de pedras no solo, dificuldades logísticas (longas distâncias), atendimento técnico precário, dificuldades em obter linhas de crédito, diferentes composições de solo em uma mesma área e falta de locais para armazenamento da produção.

Foi identificado que o fato das propriedades estarem inseridas na Área de Proteção Ambiental Ilha do Bananal/Cantão é visto como algo "vantajoso" para 22\% dos entrevistados, "dificultador" para $21 \%$ e "indiferente" para $52 \%$ deles, sendo que $5 \%$ não souberam responder. Um fato relacionado a isso que chamou a atenção foi que $12 \%$ desses entrevistados manifestaram total desconhecimento sobre o fato de suas propriedades estarem inseridas na Unidade de Conservação.

A opinião unânime dos sojicultores entrevistados é que o futuro da cultura da soja na região será de contínuo crescimento. Cabe ressaltar ainda que $14 \%$ dos entrevistados relacionaram, de forma espontânea, o crescimento da cultura da soja com o desenvolvimento da região, ainda que não tenham sido indagados diretamente sobre isso.

\section{CONCLUSÃO}

Durante todo o processo de visitas às propriedades para realização das entrevistas, além das respostas específicas às perguntas dos questionários, constatou-se, ao analisar o tamanho médio das propriedades e das áreas de cultivo de soja, a estrutura necessária para o cultivo desse grão em larga escala, a demanda considerável de conhecimento técnico necessário para o desenvolvimento da atividade, a tecnologia de ponta que é empregada e os equipamentos de alto custo utilizados, que o modelo de monocultura da soja adotado na Área de Proteção Ambiental demanda profissionalismo, know-how e expressivos recursos financeiros.

Apesar de toda a riqueza gerada pela soja, essa não é uma atividade "democrática" na Área de Proteção Ambiental Ilha do Bananal/Cantão. Assim como as terras, os benefícios gerados pela monocultura em larga escala demonstraram estar concentrados nas mãos de poucos latifundiários que geram poucos empregos diretos, muitos dos quais absorvem grande parte da mão de obra especializada de outros Estados, uma vez que a região carece de profissionais capacitados.

Ficou evidente a dicotomia existente na Área de Proteção Ambiental. Por um lado, à expansão agrícola provedora de "emprego e renda", por outro, a missão de promover o uso sustentável dos recursos naturais na maior Unidade de Conservação do Estado, a qual claramente não é compreendida por aqueles que dela usufruem.

A ausência do Estado é percebida em ambos os lados dessa balança, que demonstra pender para o lado do agronegócio. Por um lado, o governo peca junto ao produtor pela falta de investimentos, principalmente no que diz respeito a um melhor escoamento da produção, na capacitação de mão de obra, no apoio técnico aos produtores e na implantação de programas que busquem baixar o custo de produção e agregar valor ao que é produzido. Por outro, o governo é lembrado pela ausência com que trata a questão ambiental na Unidade. A desinformação sobre a Área de Proteção Ambiental é evidente em todos os setores. Durante todos os trabalhos pelo interior da Unidade não se visualizou uma única placa que informasse que ali se tratava de uma área ambientalmente protegida e indicasse a conduta a ser adotada. 
A atual política ambiental do Estado faz com que o produtor que tem sua propriedade localizada dentro de Unidade de Conservação, seja mais onerado do que aquele que tem a propriedade fora dela, situação essa que deveria ser justamente a oposta. Para entender esse raciocínio basta considerar a Lei Estadual no 2.713, Tocantins (2013), que dispensou de licenciamento ambiental todas as atividades agrossilvipastoris do Estado, lei essa que não se aplica as propriedades localizadas no interior de Unidades de Conservação. O correto seria que o licenciamento ambiental para atividades potencialmente poluidoras fosse exigido em todo o Estado, entretanto áqueles proprietários que tem suas áreas localizadas no interior de Unidades de Conservação poderiam, por exemplo, ser isentos das taxas normalmente cobradas pelos órgãos ambientais durante a abertura e andamento dos processos de licenciamento.

É imprescindível que se estabeleça, de fato, uma política ambiental propositiva e presente na Área de Proteção Ambiental Ilha do Bananal/Cantão, envolvendo a conscientização e o comprometimento de todos os atores e baseada inicialmente em três ações:

I - Revisar a legislação ambiental do Estado de forma a salvaguardar o meio ambiente recompensando quem o preserva e punindo de fato àqueles que o destroem;

II - Realizar a revisão imediata do Plano de Manejo da Área de Proteção Ambiental Ilha do Bananal/Cantão de forma estritamente técnica, retratando a atual realidade da Unidade, inclusive considerando as áreas de uso já consolidadas;

III - Adotar uma política de desoneração, incentivo e valorização das propriedades localizadas em Unidades de Conservação e demais áreas ambientalmente protegidas, desde que mantenham uma conduta ambiental correta de acordo com as normas da Unidade. Essas medidas podem ser pagamentos por serviços ambientais prestados e agregação de valores aos produtos e serviços gerados nessas propriedades, como a certificação de qualidade ambiental (selo verde) ou ainda a redução de impostos, repasses de percentuais do ICMS Ecológico obtido pelos municípios em função destes possuírem áreas protegidas em seus limites, etc.

Os benefícios gerados pela preservação do meio ambiente não se atém a fronteiras, não diferencia classes sociais, nem reconhece interesses individuais, trata-se de um benefício igualitário e democrático.

\section{CONTRIBUIÇÃO DOS AUTORES}

Os autores DCM e FBG participaram da coleta e organização dos dados, planejados pelos autores DCM e EC. O autor DCM analisou os dados e elaborou o manuscrito, com suporte do autor EC na análise, escrita e revisão final do mesmo.

\section{CONFLITO DE INTERESSE}

Os autores declararam que não há conflito de interesse.

\section{FINANCIAMENTO}

Os autores informaram que não receberam suporte financeiro para o desenvolvimento da pesquisa.

\section{REFERENCIAS BIBLIOGRÁFICAS}


Alves, V.E.L. (2015). Modernização e Regionalização nos Cerrados do Centro-Norte do Brasil. Consequência Editora: Rio de Janeiro.

APROSOJA - Associação dos Produtores de Soja do Brasil. Disponível em: <http://aprosojabrasil.com.br/2014/sobre-a-soja/uso-da-soja/> Acesso em: 08/07/16.

BRASIL. Lei n. 9.985, de 18 de julho de 2000. (2010). Institui o Sistema Nacional de Unidades de Conservação da Natureza. Legislação Brasileira sobre Meio Ambiente - 3. ed. Centro de Informação e Educação. Edições Câmara, Brasília.

BRASIL. CONAB - COMPANHIA NACIONAL DE ABASTECIMENTO. (2017) Séries Históricas: Séries históricas de Área Plantada, Produtividade e Produção, relativas às safras de 1976/1977 a 2015/2016 de Grãos, 2001 a 2016 de Café, 2005/2006 a 2016/2017 de Cana-de-açúcar. Disponível em: <http://www.conab.gov.br/conteudos.php?a=1252>. Acesso em: 01 nov. 2017.

Carvalho, R.A. (1999). Amazônia rumo ao "ciclo da soja". Amazônia Papers n. 2, Programa Amazônia, Amigos da Terra, São Paulo, Brasil. 1999.

CONAB - Companhia Nacional de Abastecimento. (2016). Acompanhamento da Safra 2015 / 2016 9o Levantamento. Tocantins: CONAB.

Da Silva, A.R.P., \& Almeida, M.G. (2007). O agronegócio e o Estado do Tocantins: o atual estágio de consolidação. Caminhos de Geografia, 8(21), 28-45.

EPE - Empresa de Pesquisa Energética. (2016). Balanço energético nacional 2016: ano base 2015. Ministério de Minas e Energia.

Fornaro, A.C. (2012). Logística e agronegócio globalizado no Estado do Tocantins: um estudo sobre a expansão das fronteiras agrícolas modernas no território brasileiro. 2012.

IBGE - Instituto Brasileiro de Geografia e Estatística. (2010). Disponível em: <http://www.ibge.gov.br/estadosat/perfil.php?sigla=to> Acesso em 15/04/16.

IBGE - Instituto Brasileiro de Geografia e Estatística. (2014). Disponível em: <http://www.geoftp.ibge.gov.br/cartas_e_mapas/mapas_regionais/sociedade_e_economia/a mazonia_legal/amazonia_legal_2014.pdf> Acesso em 09/02/17.

IBGE - Instituto Brasileiro de Geografia e Estatística. (2016). Disponível em: <http://cidades.ibge.gov.br/v3/cidades/home-cidades> Acesso em 07/12/16.

Medeiros, R. (2006). Evolução das tipologias e categorias de áreas protegidas no Brasil. Ambiente \& Sociedade, 9(1), 41-64.

Myers, N. (1988). Threatened biotas: "hotspots" in tropical forests. Environmentalist, 8(3), 187-208. Nascimento, J.B. (2013). Tocantins: história e geografia. Goiânia: Bandeirante. 
Rocha, J.C.S. (2012). Dinâmica de ocupação no bioma cerrado: caracterização dos desmatamentos e análise das frentes de expansão.

Santos, C.E., Kist, B.B., Carvalho, C., Mendes, L., \& Beling R.R. (2015). Anuário brasileiro da soja 2015. Ed. Gazeta Santa Cruz, Santa Cruz do Sul, Brasil.

Santos, F.C. dos. (2003). Caracterização socioeconômica e de recursos naturais do município de Pium-TO para fins de desenvolvimento rural. Planaltina: Embrapa Cerrados. 54p. (Documentos 82).

SEAGRO - Secretaria do Desenvolvimento da Agricultura e Pecuária do Estado do Tocantins. Cenário e perspectivas para o agronegócio da pecuária tocantinense. (2016). Relatório Técnico. Disponível em: <http://seagro.to.gov.br/agronegocios/agricultura/> Acesso em 23/05/16.

SEINF - Secretaria de Infraestrutura do Governo do Estado do Tocantins. (2000). Plano de gestão da Área de Proteção Ambiental - APA Ilha do Bananal/Cantão. Palmas: SEINF. v.1-5.

SEMARH - Secretaria de Meio Ambiente e Recursos Hídricos do Estado do Tocantins. (2016). GESTO - Gestão das Unidades de Conservação do Estado do Tocantins. Disponível em: <http://www.gesto.to.gov.br/> Acesso em 24/06/16.

SEPLAN - Secretaria do Planejamento do Estado do Tocantins. (2008). Atlas do Tocantins: subsídios ao planejamento da gestão territorial. 5o ed. Palmas: SEPLAN, 62.p.

SEPLAN - Secretaria do Planejamento e da Modernização da Gestão Pública do Estado do Tocantins. (2012). Diretoria Geral de Pesquisa e Zoneamento Ecológico-Econômico. Diretoria de Zoneamento Ecológico-Econômico (DZE). Estado do Tocantins: Áreas de Uso Legal, Restrito e Potenciais à Conservação Ambiental - Tabelas e Mapas Síntese. Palmas: SEPLAN/DZE, julho/2012. $44 \mathrm{p}$.

SEPLAN - Secretaria do Planejamento e Orçamento do Estado do Tocantins. (2016). Zoneamento Ecológico-Econômico: Inventário Socioeconômico. Palmas: SEPLAN, 2016. 408.p.

TOCANTINS. Lei n. 907, de 20 de maio de 1997. Cria a Área de Proteção Ambiental - APA Ilha do Bananal/Cantão, e dá outras providências. Diário Oficial do Estado do Tocantins, Palmas, 20 maio. 1997. n. 599, p. 7498.

TOCANTINS. Lei n. 2.713, de 09 de maio de 2013. Institui o Programa de Adesão Ambiental de Propriedade e Atividade Rural - TO-LEGAL, e adota outras providências. Diário Oficial do Estado do Tocantins, Palmas, 16 maio. 2013. n. 3.876, p. 02. 